\title{
ECONOMIC IMPACT OF URBAN TRAFFIC CONGESTION ON THE MAIN ROUTES IN MANSOURA CITY, EGYPT
}

\author{
Alaa Gabr ${ }^{1,3}$, Ahmed Shoaeb ${ }^{1,2}$, Sherif El-Badawy ${ }^{1}$ \\ ${ }^{1}$ Public Works Engineering Department, Faculty of Engineering, Mansoura University, Egypt \\ ${ }^{2}$ Nile Academy for Engineering, Mansoura, Egypt \\ ${ }^{3}$ Civil Engineering Department, Higher Institute of Engineering and Technology, New Damietta, Egypt
}

Received 31 January 2018; accepted 3 April 2018

\begin{abstract}
Traffic congestion is a major problem in most of the large Egyptian cities. This research paper focused on estimating the economic impact of the traffic congestion in Mansoura city. A traffic questionnaire was formulated and handed to various vehicle drivers and passengers. The questionnaire inquired about ideal travel time, actual travel time for each mode of transport, fuel consumption, non-recurring travel delay due to crashes and road restrictions, percentage of injured people due to road congestion accidents, and traffic offenses due to traffic congestion pressure. A field study was also conducted on some of the main arterials in the city (Suez canal street, El-Gesh street, El-Gomhoria street and AlMashaya street) to measure the geometric design elements, traffic volume, and speeds. Traffic volume was counted over 16 hours in a working day and the average vehicle operating speed was measured during free-flowing and peak periods. These measurements were used in the calculation of travel time delay cost, excess fuel consumption cost, and excess emissions cost due to congestion. Results showed that traffic congestion on the studied links costs about 184.5 million Egyptian Pounds (EGP) annually. This result shows that the chronic congestion problem in the city not only influence the daily life of the people but also drastically affects the economy of the country.
\end{abstract}

Keywords: traffic congestion, Mansoura, delay, cost, travel time, transport mode.

\section{Introduction}

Traffic congestion is a major problem in Mansoura city, the capital of Al-Dakahlia governorate. Mansoura with an area of 371 $\mathrm{km}^{2}$ is located about $120 \mathrm{~km}$ northeast of Cairo on the east bank of the Damietta branch of the Nile in the Delta region. Approximately 480,500 capita live in the city (CAPMAS, 2015; Shoeab et al., 2016). The city hosts Mansoura University with its educational/research institutions and hospitals, which attracts more than 150,000 students/employees/patients daily. In addition to the educational and medical services, Mansoura city introduces social, business, and recreational activities to the society in the Nile Delta region. These activities and the distinctive location of the city in the Delta region bring more traffic pressure in most days over the year. CAPMAS (2015) reported that AlDakahlia governorate is the fourth Egyptian governorate in the number of licensed vehicles $(\approx 421,748$ vehicles) and grows each year which causes traffic congestions especially at peak periods in the main arterial streets.

\footnotetext{
${ }^{1}$ Corresponding author: eng-alaa1400@mans.edu.eg
} 


\section{Literature Review}

During the morning, there are much stress on passengers going to work due to delays caused by traffic congestion. In addition, the afternoon rush hour is again a frustrating time because the workday is done and people want to get home for relaxation. Downs (2004) and Weisbrod and Reno (2009) defined congestion as the situation when traffic is moving at speeds below the speeds at designed capacity of a roadway, and hence the number of vehicles trying to use the road exceeds the traffic network capacity. El-Shourbagy and AboHashema (2000) measured the travel time, delay, and speed on two different arterials in Mansoura city by field trips at the morning and afternoon peaks. They found that the running speed decreased due to traffic congestion by $60 \%$ and $45 \%$ for the different arterials. Hansen (2001) stated that the total congestion time loss on Dutch motorways and principal highways was 19 million vehicle-hours.

Traffic congestion increases travel time and consequently the cost due to delays increases for different transport modes. These delays are divided into two main categories, the first is the recurring (daily or usual) travel time delay, which is defined as the amount of extra time spent traveling when traffic volume exceeds road capacity at a particular location during a predictable and repeated time of day. The second is the non-recurring delay which is defined as the delay due to unexpected events such as road maintenance, accidents and bad behavior of road drivers. The associated costs due to the two main traffic delay categories are illustrated in the subsequent sections.

\subsection{Travel Time Delay Costs}

World Bank (2010) estimated the traffic congestion cost on 11 corridors in Cairo city (over 15 million people). The annual recurring and non-recurring cost for the 11 corridors was 2.6 billion Egyptian Pounds (EGP). For greater Toronto and Hamilton area with a total population of over 6 million people, these costs were found, in 2006, to be 2.25 billion Canadian $\$$ for auto users and 337.104 million Canadian $\$$ for transit users (GTTA, 2008). Chang and Xiang (2003) selected some arterial roads for measuring accident frequency at peak and free-flowing hours. They found that the average accident frequency during peak hours was higher than that during off-peak hours on all sample arterials. An increase of accident frequency is associated with increase of non- recurring travel time delay, and hence an increase of overall travel time delay cost. BITRE (2009) selected different major urban metropolitan and non-metropolitan areas in all states in Australia and calculated the delay costs for different transport modes. In a complement study to BITRE (2009), Risbey et al. (2010) estimated the cost of non-recurring travel delay due to accidents for 122,000 reported crashes in 2006 in metropolitan areas and freeway crashes in non-metropolitan areas in Australia. Crash location, time of day, severity outcome and traffic flows by road type were used for the non-recurring delay estimation. The estimated cost was 792 million Australian \$, which was about $4.5 \%$ of the crash cost.

\subsection{Vehicle Operating Cost due to Delays}

As traffic congestion occurs on roads, more fuel is being consumed. This wasted quantity of fuel leads to extra 
costs. Additionally, vehicle maintenance costs increase due to more depreciation, which also occurs at peak periods (World Bank, 2010). TAG (2014) concluded that at low speeds (during peak periods) the fuel consumption increased to about 15 liters $/ 100 \mathrm{~km}$ travelled and reduced gradually with increase of speed. The World Bank (2010) study on Cairo's 11 corridors, estimated the total excess gasoline, diesel consumption and excess fuel subsidy costs to be 2.85 billion EGP yearly. In another study conducted by (Khan and Islam, 2013), the total annual cost of burnt fuel due to congestion in Dhaka city was estimated to be 178.6 million US Dollars (USD). Barnes and Langworthy (2003) estimated the maintenance cost for the new brands of passenger cars, light, and commercial trucks based on five-year life-cycle costs. They used the available data from the manufacturers' recommended maintenance schedule, national labor-rate averages, and manufacturers suggested list price for spare parts. They found that the maintenance cost values were $0.17,0.22$, and 0.49 USD per mile for passenger cars, light trucks and trucks, respectively. RACQ (2015) found that the average repair cost for different private vehicles that passed $15,000 \mathrm{~km}$ annually was 8.8 cents/mile. AAA (2015) estimated the average cost for owning and operating automobiles over a five-year personal use of a vehicle or 75,000-mile ownership period. The average maintenance cost included oil cost was 5.1 cents/mile based on the prices in 2013. Litman (2013) concluded that the vehicle maintenance cost in Melbourne city, Australia for urban peak travel was $15 \%$ more than the urban off-peak travel.

\subsection{Excess Emission Cost due to Traffic Delay}

There are five main pollutants emitted from vehicle operations such as carbon dioxide $\left(\mathrm{CO}_{2}\right)$, carbon monoxide (CO), $\mathrm{PM}_{10}$; particles with a diameter of 10 micrometers or less that can be suspended in air, nitrogen dioxide (NO) and sulfur dioxide (SO) (Mallela and Sadasivam, 2011). Ali (2010) conducted a study on 20 air-quality monitoring stations in Greater Cairo to measure pollutants such as $\mathrm{PM}_{10}$. $\mathrm{He}$ found that the concentration of $\mathrm{PM}_{10}$ in air ranged from 114 to $162 \mu \mathrm{g} / \mathrm{m}^{3}$. Ibrahiem (2015) found that the marginal damage costs to human health because of SO, NO, $\mathrm{PM}_{10}$, and $\mathrm{PM}_{2.5}$ (fine particles with a diameter of 2.5 micrometers or less) pollutants were 5446, 7261, 22102, and 34037 USD/ton, respectively. RWDI (2006) estimated the marginal damage costs to human health due to $\mathrm{CO}, \mathrm{PM}_{2.5}$, and $\mathrm{O}_{3}$ in Vancouver $\mathrm{BC}$ region, Canada to be 205, 317000, and $1086 \mathrm{Canadian \$ /ton,} \mathrm{respectively.}$ Mallela and Sadasivam (2011) adopted the EMFAC (EMission FACtors) model that was developed by the California Air Resource Board (CARB) to estimate the emission rates in $\mathrm{gm} / \mathrm{mile}$ for most pollutants $(\mathrm{CO}$, $\mathrm{SO}, \mathrm{NO}$, Vehicle Operating Cost (VOC), $\mathrm{PM}_{10}$ ) generated in California from auto and trucks based on the vehicle average speed.

\subsection{Traffic Offenses Cost}

TAC (2014) conducted a study on congestion cost related offenses in Hong Kong. Authorities applied fixed penalty charges that were set at 320 USD or 450 USD for illegal parking, loading and unloading of 
goods or picking up passengers in restricted zones. When there are traffic jams or lack of parking spots, drivers in Egypt, commit more traffic offenses due to congestion. The new Egyptian traffic rules that were released by (The Parliament, 2008) regulate the misbehavior of drivers by applying an offense of at least 1000 EGP and 200 EGP to whoever drives in opposite direction and parks illegally.

\subsection{Waiting Time Delay Cost}

Waiting and transferring are perceived more burdensome than travelling. Indeed, out-of-vehicle times appear longer than in-vehicle time (IVT). Wardman (2004) conducted a study on waiting time effect and found that trip length and trip purpose affect waiting time values. Wait time value increases slightly with trip duration for transit walk and wait and appears longer for cars than other transit riders. Waiting time was estimated to be about 2.5 times the value of IVT during congestion. Lagune-Reutler et al. (2016) conducted a questionnaire with 822 responses regarding observed wait times in urban study area. Approximately half of respondents actually waited less than 5 minutes, a third waited between 5 and 10 minutes, $8 \%$ waited between 10 and 15 minutes, and the rest waited between 15 and 30 minutes.

\section{Objectives}

The main objective of this study is to estimate the total (direct and indirect) annual traffic congestion costs on the main urban corridors in Mansoura city, Egypt for home based work (HBW) trips. A secondary aim was to suggest recommendations to Dakahlia governorate on the short and long-terms for diminishing the economic impact of traffic congestion in Mansoura city. The direct costs are related to travel time delays such as traffic delays cost, excess fuel consumption cost, excess emissions cost due to traffic congestion. The indirect traffic congestion costs are associated to road safety, health and environmental impacts as vehicle maintenance cost, lost productivity of injured people due to traffic congestion crashes, waiting delay time cost and traffic offenses cost.

\section{Site Selection}

Mansoura University introduces many services to society in different fields. Thus, the campus and its surrounding area are considered the main traffic generators in the city. Most of the work/education trips end at Mansoura University through ElGesh, El-Gomhoria, Al-Mashya, and Suez Canal streets, which represent the main corridors in Mansoura city. Therefore, this path (from Gedella to Mansoura University) as shown in Fig. 1 was chosen as a case study, since it accommodates a great deal of attraction for the $\mathrm{HBW}$ trips in Mansoura. The investigated path starts from Suez Canal street as origin to Mansoura University as destination through El-Gesh, El-Gomhoria and Al-Mashaya streets with a total length of about $5.5 \mathrm{~km}$. This link has a very high volume of traffic, and different transport modes (private cars, taxis, micro/mini buses, light commercial vehicles and motorcycles). In addition, this link accommodates traffic coming from the east direction of the city from other governorates. The opposite direction from Mansoura University to Gedelya represents the work-home trips, which are not studied in this research study. 


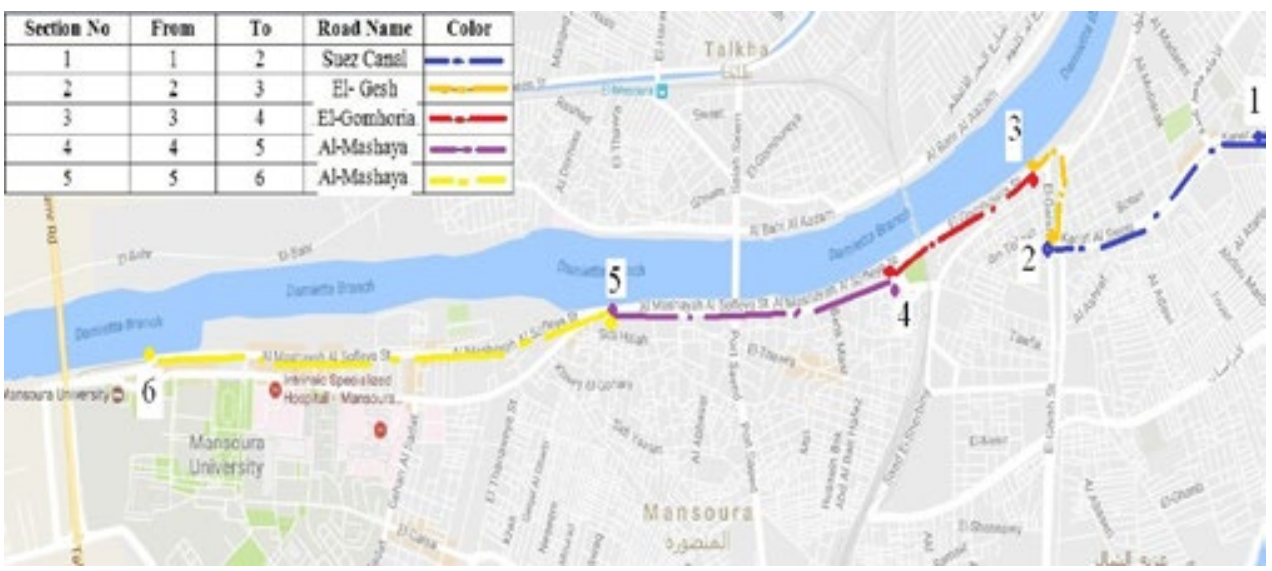

Fig. 1.

Study Area and Corridors

Source: (Google maps)

\section{Research Methodology}

Fig. 2 illustrates the methodology followed in this study. The work plan was divided into three main parts:

First part describes the traffic questionnaire conducted on road users (drivers and passengers) within the study area to determine Value Of Time (VOT) of each road user, delays at the same locations during congestion, delays due to unexpected events, fuel economy of each fuel type used by vehicles, average monthly maintenance cost of vehicles, percentage of drivers committing traffic offenses at peak periods, and percentage of injured people due to traffic congestion crashes and its corresponding injury level. Second part refers to the collected data for the studied corridors such as cross section elements, traffic volumes at morning and afternoon peaks, traffic flow characteristics at each period, average speed at peak and off-peak periods, the $85^{\text {th }}$ percentile speed and hence free-flow speed at each studied corridor.

\section{Data Collection}

Traffic questionnaire was designed in Arabic language and delivered to various drivers and passengers in Mansoura city to collect data needed to achieve the study objectives. The questionnaire forms were handed during the 2015/2016 academic year between September and December, since traffic congestion increases during the academic season. The questionnaire forms were distributed during working hours at stations around studied path. Some forms were posted online using Google forms. The total number of surveyed persons was 613 representing a confidence level of about $95 \%$ according to the formula found in (Bartlett et al., 2001) Eq. (1):

$n=\left(Z^{2} * p *(1-p)\right) / d^{2}$

Where, $\mathrm{n}$ is the sample size; $\mathrm{Z}$ is the standard normal derivative value ( 1.96 for $95 \%$ confidence level); $\mathrm{p}$ is the percentage picking a choice in decimal; and $\mathrm{d}$ is the confidence interval in decimal. 
The questionnaire was divided into five sections as follows:

- First section refers to general introduction about passenger and driver profession, and transport mode to work.

- Second section covers the extent of suffering from the traffic congestion problem and its causes on the studied path. It also inquiries about the recurring and non-recurring delays, average waiting times and applied penalties on salary due to delays to work
- Third section evaluates the monthly income, monthly working hours, and recurring travel delays to calculate time value for different drivers and passengers

- Fourth section includes vehicle operating costs such as fuel consumption and maintenance

- Fifth section asks about accident rates, causes, collision types, and traffic offenses that may be applied due to congestion. It also covers the injured people due to traffic accidents and the corresponding injury level

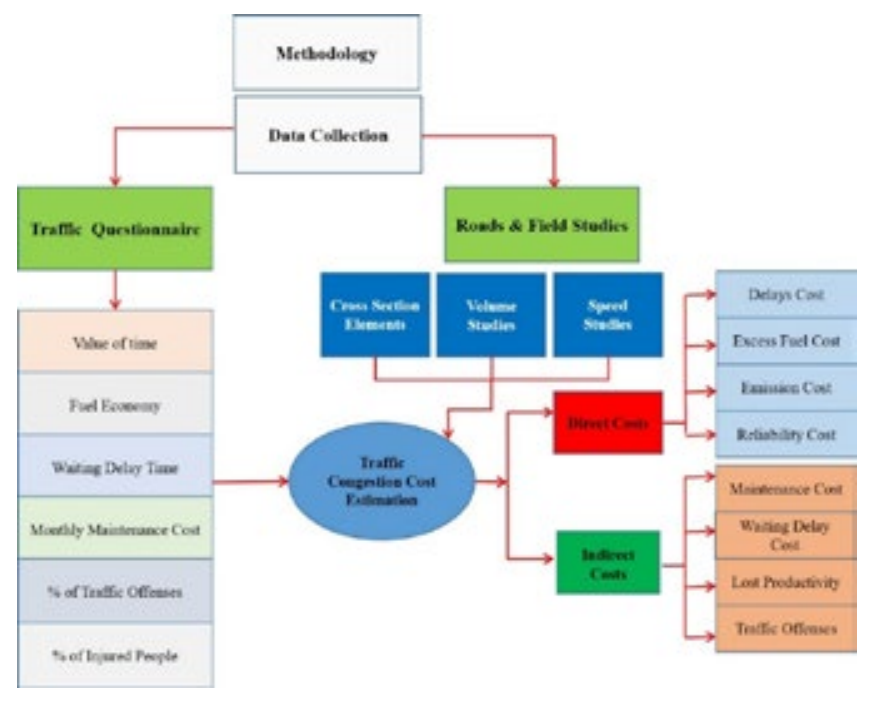

Fig. 2.

Research Methodology Flow Chart

It was also important to collect field data regarding the cross section elements of the studied corridors, traffic volumes, average peak speed, and average speed at freeflowing periods. Traffic volume counts were conducted on the four main links over 16 hours in an ordinary day using a video camera. Average speeds were measured during peak and free-flowing periods using the pavement marking (Manual method) for each road corridor (HCM, 2010). Two lines 33 meters apart were marked on the surface of the pavement and the elapsed time by each vehicle to cross the two marks was measured using a stopwatch (pen and paper technique), and hence the travel speed was estimated. The legal speed limit on each corridor was determined as the speed of $8 \mathrm{~km} / \mathrm{hr}$ 
above the $85^{\text {th }}$ percentile speed according to Forbes, (2012). Design speeds are the speeds of ( 8 to 16$) \mathrm{km} / \mathrm{hr}$ above legal speed limit based on NCHRP (2003). Measurements of speeds during the peak and free-flowing periods were used further in estimating traffic congestion costs. The floating car technique (average 10 runs for each corridor) was used on all sections to determine travel time at peak and free-flowing periods as well as estimate the travel time reliability and scheduling. Reliability of travel time is the standard deviation of the travel time divided by the average travel time (AustRoads, 2016). While, scheduling is defined as the $90^{\text {th }}$ percentile travel time divided by the average travel time (AustRoads, 2016).

\section{Results and Analysis}

The questionnaire discussed three types of delays as follows:

- Recurring or systematic delays of working trips which vary between transport modes. As shown in Fig. 3 , the microbuses had the maximum recurring delay (about $23 \mathrm{~min}$./trip/day) due to systematic stops, large number of passengers, and microbuses' drivers bad driving behavior. In average, recurring delay for other transport modes was about $16 \mathrm{~min}$./trip/day as shown in Fig. 3. The symbol (I) in the Figure represent the standard deviation of delay time

- Average non-recurring travel delay time due to unexpected events ranged between 7 and 10 minutes for different transport modes

- Passenger responses related to waiting delay time showed that $45.5 \%$ of road passengers waited at stations during peak periods for 5 to 15 minutes, $20.2 \%$ of passengers waited about 16 to 25 minutes, $5.8 \%$ of passengers waited for 26 to 35 minutes, $7.5 \%$ of passengers waited for more than 35 minutes, and only $12.7 \%$ of passengers waited less than 5 minutes

Table 1 presents the data of the cross-section elements for each corridor, traffic volume, and speed. Based on HCM (2010), traffic density, Peak Hour Factor (PHF), flow rate and level of service (LOS) were calculated for each studied section. Daily traffic was computed by adding all the 16 hours traffic volumes plus the 8 hours traffic volumes, which were assumed to be about 2 to $3 \%$ of the whole day for urban routes (FHWA, 2014).

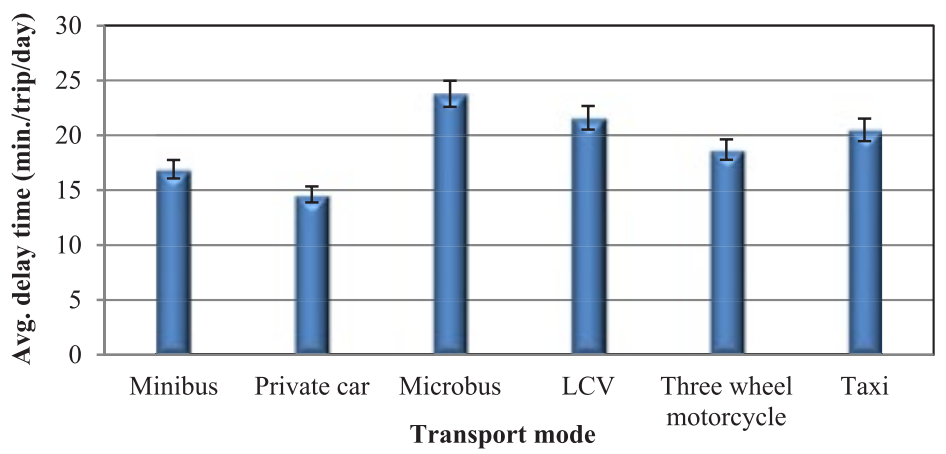

Fig. 3.

Observed Average Recurring Travel Time Delay for Each Transport Mode 
Table 1

Data of the Field Study for Each Corridor

\begin{tabular}{|c|c|c|c|c|c|}
\hline \multirow{2}{*}{ Property } & \multirow{2}{*}{$\begin{array}{c}\text { Suez Canal } \\
\text { st. }\end{array}$} & \multirow{2}{*}{ El-Gesh st. } & \multirow{2}{*}{\begin{tabular}{|c} 
El-Gomhoria \\
st.
\end{tabular}} & \multicolumn{2}{|c|}{ Al-Mashaya } \\
\hline & & & & Sec. 1 & Sec. 2 \\
\hline Length (m) & 1600 & 300 & 700 & 900 & 2000 \\
\hline Lane width (m) & 3.75 & 3.65 & 3.5 & 3.75 & 3.75 \\
\hline No. of lanes/direction & 2 & 3 & 2 & 2 & 3 \\
\hline On-street parking width $(\mathrm{m})$ & 4 & 2 & - & - & 4 \\
\hline Right lateral clearance (m) & 2 & 1 & 0.8 & 1 & 1.5 \\
\hline Left lateral clearance $(\mathrm{m})$ & 1 & 1 & 0.8 & 1 & 1.5 \\
\hline Road type & \multicolumn{5}{|c|}{ Urban major arterial } \\
\hline Median type & Raised & Raised & Raised & None & None \\
\hline Median width (m) & 17 & 30 & 0.6 & - & - \\
\hline Access points $/ \mathrm{km}$ & 6 & 3 & 1 & 1 & 5 \\
\hline Peak traffic volume, veh/hr & 3071 & 3218 & 3343 & \multicolumn{2}{|c|}{3515} \\
\hline Daily traffic (veh/day) & 40067 & 44580 & 39989 & \multicolumn{2}{|c|}{30267} \\
\hline Peak hour factor & 0.95 & 0.97 & 0.99 & \multicolumn{2}{|c|}{0.96} \\
\hline Peak flow rate $(\mathrm{pcu} / \mathrm{hr})$ & 3233 & 3318 & 3377 & \multicolumn{2}{|c|}{3661} \\
\hline Road density (pcu/km/ln) & 41.4 & 25.7 & 34.8 & 50.3 & 33.9 \\
\hline Average speed $(\mathrm{km} / \mathrm{hr})$ & 14.5 & 14.1 & 22 & 14.2 & 8 \\
\hline off-peak $85^{\text {th }}$ percentile speed $(\mathrm{km} / \mathrm{hr})$ & 20 & 24 & 32 & 22 & 20 \\
\hline Design speed $(\mathrm{km} / \mathrm{hr})$ & 40 & 45 & 50 & 40 & 40 \\
\hline Speed limit $(\mathrm{km} / \mathrm{hr})$ & 30 & 35 & 40 & 30 & 30 \\
\hline Base free flow speed $(\mathrm{km} / \mathrm{hr})$ & 41.2 & 46.2 & 51.2 & 41.2 & 41.2 \\
\hline Free flow speed $(\mathrm{km} / \mathrm{hr})$ & 39.1 & 43 & 48.5 & 36.4 & 36 \\
\hline
\end{tabular}

Fig. 4 presents an example of the 15-minute traffic flow rate for each vehicle class at morning peak on Suez Canal street. Looking at Table 1 , flow rate was calculated based on HCM (2010) by dividing the observed traffic volume at peak period over the corresponding PHF for each section. Density was calculated by dividing the flow rate over corresponding average travel speed. The LOS was determined for each corridor based on the HCM (2010) according to the average travel speed and density values, which was found to be "F" for all corridors. This was due to the high traffic density values on all studied corridors and the unstable and variable flow rate. As given in Table 1, average travel speed was found to be $14.5 \mathrm{~km} / \mathrm{hr}$, $14.1 \mathrm{~km} / \mathrm{hr}, 22 \mathrm{~km} / \mathrm{hr}, 14.2 \mathrm{~km} / \mathrm{hr}$ and $8 \mathrm{~km} / \mathrm{hr}$ for Suez Canal street, El-Gesh, El-Gomhoria, Al-Mashaya Sec. (1) and
Al-Mashaya Sec. (2), respectively. FFSs were determined in accordance with the HCM (2010) for urban multilane highways. Furthermore as seen in Fig. 4, passenger cars represent more than $60 \%$ of the traffic volume, followed by taxis, which represent more than $20 \%$ of the traffic volume at peak periods on Suez Canal street. Microbuses and minibuses have $6 \%$ to $9 \%$ of the traffic volume at daily peak periods. Three wheel motorcycle represented about $7 \%$ of traffic volume and light commercial vehicles have the least percentage (4\%). Thus, private cars and taxis had high impact on congestion costs due to their high percentages and the corresponding high daily working trips especially at rush hours. This also indicates the poor public transportation system in the city and the high dependency on private cars and taxis, which contribute more to the congestion problem in the city. 


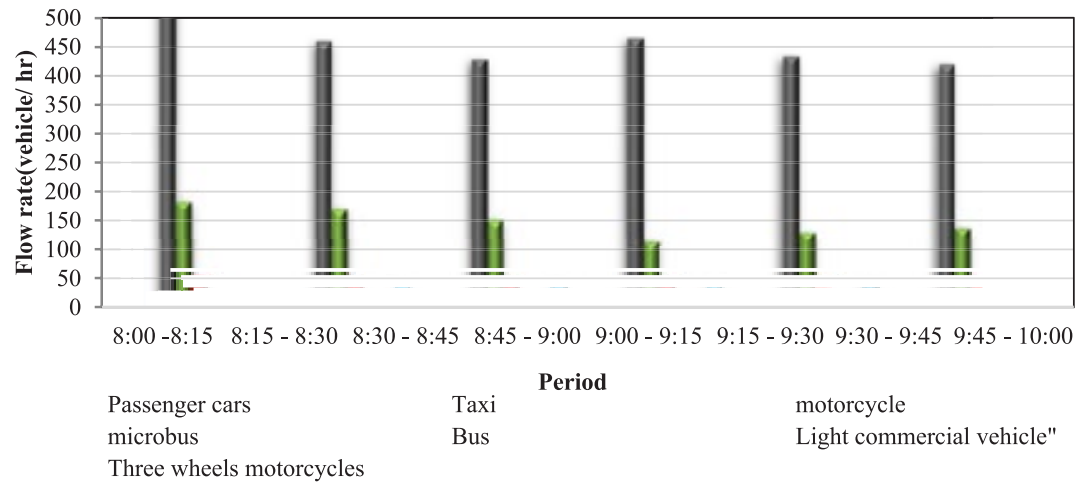

Fig. 4.

Flow Rate by Vehicle Class on Suez Canal Street at (8-10) AM

\subsection{Direct Congestion Costs}

Measurements of traffic volumes, speeds, and the geometry of the cross-section as well as the questionnaire results were employed to estimate the direct congestion costs for the path from Gedyla to Mansoura University. These costs include costs of recurring and non-recurring travel time delay, vehicle operation, fuel consumption, and excess emission. The following sections present the approaches used to estimate these costs based on the collected data for the studied path.

\subsubsection{Working-Trips Recurring and Non- Recurring Travel Time Delay Costs}

By knowing the monthly income and number of working hours per month from the traffic questionnaire, the VOT for passengers and drivers using different transport modes was calculated.

Fig. 5 shows the calculated VOT for both drivers and passengers for each transport mode. The symbol (I) in the Figure represent the standard deviation of VOT values.

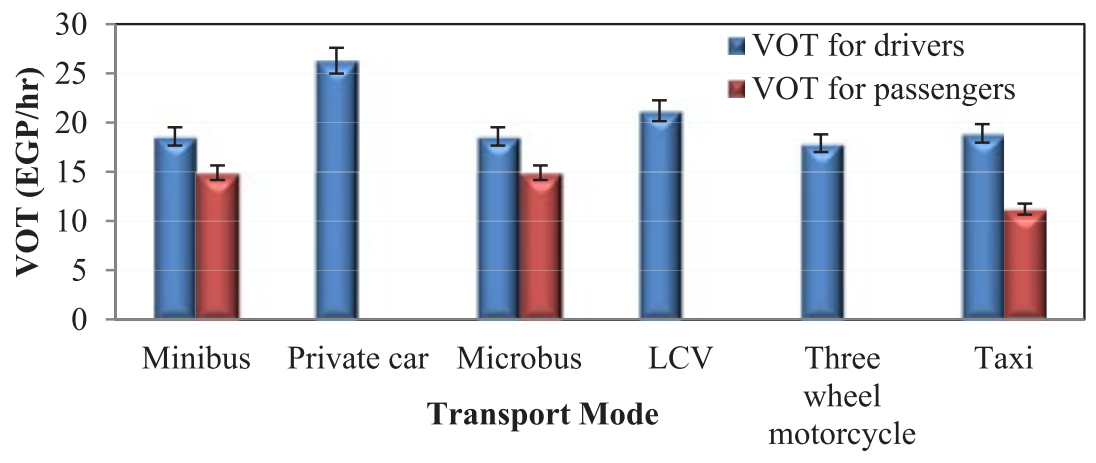

Fig. 5.

VOT for Passengers and Drivers of Each Transport Mode 
It can be seen from Fig. 5 that the average hourly VOT for each passenger and driver per each transport mode was within the range of 15 to $25 \mathrm{EGP} / \mathrm{hr}$. The highest value of time was for private car owners due to their high level of income (27 EGP/ $\mathrm{hr}$ in average). CAPMAS (2015), reported the average VOT for public and private employees as 14.1 EGP/hr in Egypt. Eq. (2) (World Bank, 2010) was used to calculate the recurring business travel time delay as follows:

Recurring vehicle hour delay $/$ day $=\frac{\text { Peak period congested DVKT }}{\text { Average peak period speed }}-\frac{\text { Peak period congested DVKT }}{\text { Average off }- \text { peak speed }}$

Where; DVKT: daily vehicle kilometer travelled at peak periods, which equals traffic volume at peak period multiplied by road length in kilometers.

Recurring travel time delay values were found to be $1.49,0.48,0.51,1.2,8.5$ minutes/trip for Suez canal st., El-Gesh st., El-Gomhoria, Al-Mashaya (sec. 1) and Al-Mashaya (sec. 2), respectively. Average number of working trips per one work shift was estimated based on the questionnaire results by calculating the number of daily working hours and trip time (at peak and free-flowing periods) for each driver of microbus, minibus and taxi. Microbus and minibus are using specific path, which is the studied link, while taxis make trips all over the city. Therefore, a specific question was asked to taxi drivers about how many trips they make on the studied link to determine the number of trips per day. The average number of working trips were found to be $22,22,8$, and 71 trip per day for minibus, microbus, taxi, and threewheel motorcycle, respectively assuming two work shifts per day. The number of trips for the three-wheel motorcycle was higher than other transport modes because threewheel motorcycle drivers makes only short trips on Suez Canal street. Fig. 6 presents the expected recurring travel time delay cost due to congestion using Eq. (3) (Khan and Islam, 2013) for each section and each transport mode.

TTC per day $=\% W \cdot T *\left(\sum T T * V O T * O i * N i\right)+\% N . W . T *\left(\sum T T * V O T * O i * N i\right)$

Where; TTC: travel time cost; W.T is the working trips (assumed to occur during peaks only); N.W.T is the non-working trips calculated from surveys with different VOT for a particular vehicle type, i; TT travel time delay, hr; $\mathrm{O}$ is the passenger occupancy of the vehicle, $\mathrm{i}$ and $\mathrm{N}$ is the number of vehicles, $\mathrm{i}$.

That cost was estimated based on the conducted field measurements, traffic composition for each corridor, VOT for each transport mode, and the calculated travel time delay from Eq. (2). This cost was calculated for each mode by multiplying the DVKT at peak periods per day by the percentage of each transport mode by the VOT for transport users (drivers or passengers) by the number of daily work trips for each mode on the studied section over 250 days per year. Both taxi and private car modes showed the highest delay cost, respectively due to the highest number of taxi and private cars, their relatively high VOT. Al-Mashaya corridor had the highest 
annual travel time delay cost with a value of about 43.2 million EGP due to the higher value of delay time. The delay costs for the three wheel motorcycle and LCV were very low compared to cost values of other transport modes as most drivers of three wheel motorcycles take illegal paths during peak periods. The total annual recurring delay cost for all corridors was about $\mathbf{5 6 . 2}$ million EGP.

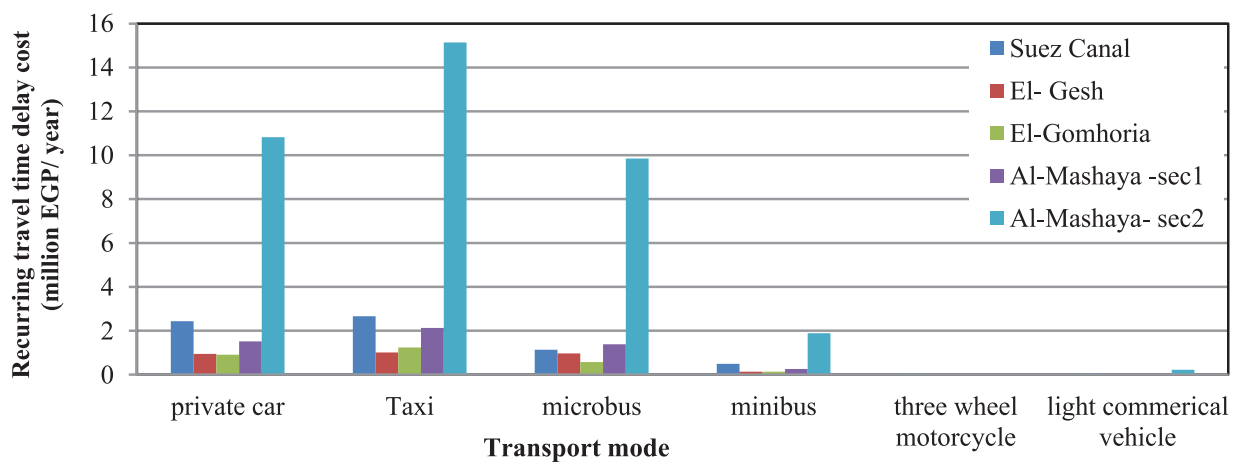

Fig. 6.

Recurring Travel Time Delay Co st for All Transport Modes for Each Corridor

The non-recurring travel time delays due to crashes, and unexpected events were computed from the conducted traffic questionnaire for each transport mode. The non-recurring travel time delays were found to be 7, 9.6, 9.1, 8.9 and 5 minutes for taxi, minibus, microbus, light commercial vehicles and private cars, respectively. Due to the lack of data on crash locations, times, and severity outcomes, Eq. (3) was used to determine the non-recurring travel time delay cost in a similar way to the calculation of recurring travel time delay cost. The total estimated annual non-recurring travel time delay costs were $6.96,11.44,9.72$, and 7.64 million EGP for Suez canal st., El-Gesh st., El-Gomhoria st, and Al-Mashaya st., respectively.

\subsubsection{Reliability Cost}

Reliability is a variation around trip travel time at peak period whether one arrives early or late (World Bank, 2010). World Bank (2013) assumed a monetization factor that is used for converting variation of travel time at peak periods to equivalent value of travel time. This factor varies according to transport mode as follows:

- Passenger cars and motorcycles: 1.0-minute travel time variation is equivalent to 0.9 minute in travel time.

- Public transport including taxis: 1.0 -minute travel time variation is equivalent to 1.1 minutes in travel time.

Eq. (4) was used to calculate the economic cost of reliability using the average peakspeed and the volume of vehicles at peak periods (World Bank, 2013). The annual reliability cost was calculated for each studied corridor at peak periods, which were $2.73,1.64,2.96$, and 6.57 million EGP for Suez canal, El-Gesh, El-Gomhoria and AlMashaya streets, respectively. 
Reliability cost $=$ Monetization factor $*$ Coeficient of variation $* \frac{\text { Length of corridor }}{\text { average peak speed }} *$ vehicle occupancy

$*$ VOT $* 250$ working days $*$ volume of vehicles at peak period

\subsubsection{Excess Fuel Consumption Cost}

Based on the traffic questionnaire, the fuel consumption rate was estimated for gasoline, diesel and natural gas and found to be $0.123,0.122$ liter $/ \mathrm{km}$ and $0.113 \mathrm{~m}^{3} /$ $\mathrm{km}$, respectively. The annual excess fuel consumption was then calculated for each fuel type using Eq. (5) (World Bank, 2010) as follows:

Daily fuel wasted $($ liter $)=\frac{\text { DVKT }}{\text { Free flow travel speed }} * \frac{F F S-\text { Peak congested speed }}{\text { Average fuel economy }}$

Where, FFS is the free flow speed that represents the desired speed of drivers in low volume conditions and in the absence of traffic control devices; Average fuel economy represents the rate of consumption of fuel type during the day.

The annual excess fuel cost can then be calculated for each kind of fuel as the daily fuel wasted multiplied by liter cost (gasoline or diesel) multiplied by number of working days. The estimated total annual excess fuel consumption costs from Eq. (5) based on the fuel prices in 2017 were 1.76, 0.6, and 0.11 for gasoline, diesel, and natural gas, rspectively. Moreover, the annual excess fuel consumption for each corridor was calculated based on Khan and Islam (2013) using Eq. (6) as follows:

Cost per day $=\sum(N * A * F E * F C)$

Where: $\mathrm{N}$ is the number of vehicles of a specific fuel type, $\mathrm{F}$; $\mathrm{A}$ is the average run per day; FE is fuel efficiency (fuel Economy) and FC is fuel cost.

The values of annual excess fuel consumption cost were $0.748,0.167,0.297$, and 1.27 million EGP for Suez Canal, El-Gesh, El-Gomhoria, and Al-Mashaya streets, respectively based on Eq. (6).

\subsubsection{Excess Emission Costs}

The annual excess weight of carbon dioxide, $\mathrm{CO}_{2}$ can be calculated from Eq. (7) as described in (World Bank, 2010). Thus, the total annual excess emission cost can be determined from Eq. (8).

$W_{\mathrm{CO} 2}=G W * 2.40+D W^{*} 2.41$

$C_{\mathrm{CO} 2}=W_{\mathrm{CO} 2} * U_{\mathrm{CO} 2}$

Where; GW: Annual weight of wasted gasoline (kg), DW: Annual weight of wasted Diesel (kg), $\mathrm{U}_{\mathrm{co} 2}$ : unit cost of $\mathrm{CO}_{2}$.

The estimated unit cost of $\mathrm{CO}_{2}$ by (World Bank, 2010) was 57 EGP per ton, which requires a modification based on 2017 prices. Assuming that the annual increase in global unit price of $\mathrm{CO}_{2}$ is $1 \%$, thus the predicted price is $60.5 \mathrm{EGP} /$ ton. The $\mathrm{Co}_{2}$ emissions cost was estimated based on Eq.s (7) and (8) (World Bank, 2010), while the costs of other pollutants, $\mathrm{CO}, \mathrm{NO}, \mathrm{SO}$, and $\mathrm{PM}_{10}$ were estimated based on the emission rates detailed in (Mallela and Sadasivam, 2011). 


\subsection{Indirect Congestion Costs}

The indirect traffic congestion cost is composed of four main components as follows:

- Vehicle maintenance cost due to vehicle breakdowns that may happen at peak periods

- Waiting delay time cost of passengers at stations which proportionally increases with traffic volume increase

- Traffic offenses cost which occurred especially at peak periods due to bad behavior of road drivers, and

- Lost productivity of injured people who may be injured due to accidents

\subsubsection{Vehicle Maintenance Cost}

In accordance with the analysis of the conducted traffic surveys for the different transport modes, the average monthly vehicle maintenance cost was calculated and found to be $231,270,249,188$ and $241 \mathrm{EGP} /$ month for taxi, minibus, microbus, private cars and light commercial vehicles, respectively. These average monthly estimated costs represent the total maintenance cost during peak and off-peak periods. Litman (2013) found that the maintenance vehicle cost during peak periods was more than that during free-flowing periods by $15 \%$. In Egypt, this percentage was also confirmed by the World Bank (2013), which showed the relationship between Vehicle Operating Cost (VOC) (EGP/VKT) and average speed
( $\mathrm{km} /$ hour). The vehicle maintenance cost during peak periods was more than that at free-flowing periods by $11 \%, 20 \%$, $30 \%$, and $9 \%$ for medium cars (taxis and private cars), microbuses, minibuses, and motorcycles, respectively. The weighted average excess maintenance cost due to congestion was found to be about $15 \%$ more than that during free-flowing period. Therefore, the average vehicle maintenance cost values due to traffic congestion were corrected to be 123.6, 144.4, 133.2, 100.6, and 128.9 EGP/month for taxi, minibus, microbus, private cars and light commercial vehicles, respectively. Subsequently, the annual vehicle maintenance cost due to congestion was estimated by the summation of the multiplication of the monthly average maintenance cost during peak periods by number of months per year by the annual peak traffic volumes for each transport mode. The total annual maintenance costs were 12.4, 14.7, 14, and 10.5 million EGP for Suez Canal, El- Gesh, El-Gomhoria, and Al-Mashaya streets, respectively.

\subsubsection{Waiting Time Delay Cost}

Delays due to waiting at stations during peak periods were computed from questionnaires as $8.7,7.25$, and 10.2 minutes for taxi, minibus and microbus, respectively. Waiting time delay cost can be determined using Eq. (9). The total annual waiting time delay costs were 1.8, 2.792 .51 , and 2.14 million EGP for Suez canal, El-Gesh, El-Gomhoria, and Al-Mashaya streets, respectively.

$W c=\sum M D P H V \times \% T C \times A v g . W t \times V o \times V O T \times N o . W d$

Where; Wc: Annual waiting time delay cost; MDPHV: Maximum daily peak hour volume; \%TC: Percentage of each mode in traffic composition; Avg.Wt: Average waiting time delay for each transport mode, Vo: Vehicle occupancy of each transport mode; VOT: Value of time 
of passengers for each mode; and No.Wd: Number of working days per year (250 days).

\subsubsection{Traffic Offenses Cost}

According to the traffic questionnaires, about $55 \%$ of drivers violated the traffic rules due to congestion. About $21 \%$ of them drove in opposite direction, $28 \%$ illegally parked, and $6 \%$ violated other rules i.e., defects in car, exceeding the speed limit...etc. As mentioned previously in the literature, a penalty of 1000 EGP must be applied to anyone drives in opposite direction and a fine of 200 EGP must be applied to drivers who park illegally (The Parliament, 2008). Based on that, the annual traffic offenses cost due to traffic congestion were estimated as 1.66, 1.8, 1.71, and 1.31 million EGP for Suez canal, El-Gesh, El-Gomhoria, and AlMashaya streets, respectively.

\subsubsection{Lost Productivity of Injured People due to Traffic Congestion Accidents}

Lost productivity of injured people due to traffic congestion crashes represents a decrease or loss of annual income per person due to injury. It is related to accident severity and percentage of injured people obtained from the questionnaire results. Lost productivity cost per injury can be calculated by the multiplication of the average annual income per person by the average consumption per person by the subtracting of the average age minus productive age per person (NIT, 2016). The average computed monthly income per person from the questionnaire was found to be 2000 EGP. NIT (2016) assumed that the average age and the productive age per injury are 69 and 30 years, respectively. It was also assumed that the average consumption per person is 92 EGP per month. Consequently, the lost productivity cost was found to be $1.95,2.47,2.22$, and 1.69 million EGP/year for Suez Canal, El-Gesh, El-Gomhoria and Al-Mashaya streets, respectively.

\subsection{Final Traffic Congestion Costs}

Table 2 gives a summary of all the estimated costs due to traffic congestion for each corridor as well as the overall annual congestion cost for the studied link. The total annual direct congestion cost was about $59 \%$ of the total cost with a value of 108.9 million EGP, while the total annual indirect congestion cost was 75.6 million EGP. The annual cost of delays including recurring, non-recurring travel time and waiting delays were about $55 \%$ of the total cost. The reason for that was due to the fact that the traffic volume had the most significant contribution on the calculation of the delay cost in particular the volumes of taxis. Regardless the largest road width of Al-Mashaya section, it was observed that it had the highest total annual cost owing to the high traffic volume and road length. Vehicle operating costs for microbuses and minibuses were higher compared with other transport modes due to the higher daily number of working trips. Consequently, the annual maintenance costs ranked in second position after delays costs with $28 \%$ of the annual total cost. In short sections i.e., El-Gesh and El-Gomhoria sections, vehicle maintenance cost had slightly higher impact on traffic congestion costs rather 
than travel time delay cost especially when many microbuses stop and traffic volume increase. The annual traffic offenses costs were about $3.5 \%$ of the total annual cost. Excee fuel consumption and emissions had the lowest influence on the estimation of congestion cost. In general, the total annual cost due to traffic congestion may surpass billion EGP for all Mansoura city, since the total annual cost of only the studied link was 184.5 million EGP.

\section{Conclusions}

A total of 613 traffic questionnaires were designed and delivered to passengers and drivers to answer questions about business travel time, actual congested travel time for each vehicle type, fuel consumption, non-recurring travel time due to crashes, percentage of injured people, and value of traffic offenses. Field studies including geometric design elements, traffic volumes, and traffic speeds during peaks and off-peaks were conducted. Based on these studies, the economic impact of traffic congestion on the main path in Mansoura city was studied in terms of the estimation of the costs of recurring and non-recurring business travel time delay, excess fuel consumption, vehicle maintenance, excess emission, waiting time delay, traffic offenses, and lost productivity of injured passengers and drivers. Based on the results and analyses of this research, the following conclusions are drawn:

- About 184.5 million EGP is wasted annually due to traffic congestion on the studied path from Gedyla to Mansoura University. The highest cost of traffic congestion in the study area was due to recurring, non-recurring and waiting time delays with a share of $55 \%$ of the total annual cost. Traffic volumes and VOT showed the most impact on the estimation of delay costs. The annual maintenance cost was ranked second with $28 \%$ of the total annual cost due to the high operating cost of microbuses and minibuses

- Illegal stops of some transport modes such as taxis, minibuses and microbuses in addition to the bad behavior of some drivers increased the bottlenecks and subsequently the delay cost

- Reliabilty cost was about $6 \%$ of the total annual cost. Reliability cost is related to the total travel time (including delays) and road length. The reliability cost on El-Gesh street was about $4.1 \%$ of the total cost on this corridor, while it was about $8.7 \%$ of the total cost on AlMashaya street due to the lower delay and the shorter length of El-Gesh road

- Traffic offenses if applicable cost about $3.5 \%$ of the total annual cost and the other costs i.e., fuel consumption, emissions, lost productivity of injured people costs were about $6 \%$

In short corridors i.e., El-Gesh and ElGomhoria corridors, vehicle maintenance cost had higher impact on the traffic congestion costs rather than travel time delay cost especially when many microbuses stop and traffic pressure increased. 
Table 2

Summary of Traffic Congestion Costs on Studied Corridors

\begin{tabular}{|c|c|c|c|c|}
\hline Section & Suez Canal St. & EL-Gesh St. & EL-Gomhoria St. & AL-Mashaya St. \\
\hline \multicolumn{5}{|c|}{ Direct congestion costs (million EGP/year) } \\
\hline Recurring travel time delay cost & 6.86 & 3.10 & 2.91 & 43.26 \\
\hline Non-recurring travel time delay cost & 6.962 & 11.437 & 9.715 & 7.641 \\
\hline Reliability cost & 2.73 & 1.64 & 2.96 & 6.57 \\
\hline Excess fuel consumption cost & 0.748 & 0.167 & 0.297 & 1.270 \\
\hline Excess emission cost & 0.0344 & 0.0092 & 0.024 & 0.071 \\
\hline $\begin{array}{c}\text { Sum of average direct traffic } \\
\text { congestion cost }\end{array}$ & 17.64 & 16.67 & 15.77 & 58.79 \\
\hline \multicolumn{5}{|c|}{ Indirect congestion costs (million EGP/year) } \\
\hline Vehicle maintenance cost & 12.4 & 14.7 & 14.0 & 10.5 \\
\hline Waiting time delay cost & 1.804 & 2.791 & 2.509 & 2.138 \\
\hline Traffic offenses cost & 1.659 & 1.796 & 1.707 & 1.311 \\
\hline Lost productivity & 1.95 & 2.47 & 2.22 & 1.69 \\
\hline $\begin{array}{l}\text { Sum of indirect traffic congestion } \\
\text { cost }\end{array}$ & 17.81 & 21.76 & 20.41 & 15.64 \\
\hline $\begin{array}{l}\text { Total traffic congestion cost for each } \\
\text { corridor (million EGP / Year) }\end{array}$ & 35.45 & 38.43 & 36.18 & 74.43 \\
\hline $\begin{array}{l}\text { Total average traffic congestion cost } \\
\text { (million EGP/Year) }\end{array}$ & \multicolumn{4}{|c|}{184.5} \\
\hline
\end{tabular}

\section{Further Work}

In this study, most of the parameters related to traffic congestion were studied such as vehicle speed, traffic volume, average daily traffic volume, level of service, traffic density,... etc. More parameters should be studied in the future such as impact of faulty design of intersections on generation of traffic bottlenecks. Emission rates and noise levels should be measured as well as the incident delay factor of roads for accurate determination of excess emission, noise, and non-recurring travel time delay costs, respectively. Finally, the impact of applying some solutions regarding the regulation of traffic demand and supply on the estimation of traffic congestion costs in Mansoura city should be studied. These solutions are for example are:

- Changing days of weekly vacation and daily shift timings (staggered shifts times) for employees
- Using river transport as a good alternative to the land transport especially that most of the attraction areas are located next to the Nile River

- Adapting of natural gas as a fuel for most vehicles, since it's environmentally friendly and safe on human health rather than other fuel types, and

- Implementing of parking garages and smart techniques of parking in the areas that attract traffic based on the land use, etc

\section{References}

AAA. 2015. Your Driving Costs. American Automobile Association - AAA Exchange motor club, Heathrow. USA. Available from internet: <http:// www.exchange. aaa.com>.

Ali, H. 2010. Regulating Traffic as a Means of Reducing Atmospheric Pollution: the case of Greater Cairo, Egypt. 
In Proceeding of the Regional Workshop on Economic Incentives and Environmental Regulation in the MENA Region - Beirut.

AustRoads. 2016. Congestion and Reliability Review, Austroads Ltd., Report No. AP-R534-16. Available from internet: <https://www.onlinepublications.austroads. com.au>.

Barnes, G.; Langworthy, P. 2003. The per-mile costs of operating automobiles and trucks. Report No. (MN/RC 200319). Minnesota Department of Transportation-Office of Research Services, \& State and Local Policy ProgramHumphrey Institute of Public Affairs, Ireland. 46 p.

Bartlett, J.E.; Kotrlik, J.W.; Higgins, C.C. 2001. Organizational research: Determining appropriate sample size in survey research, Information Technology, Learning, and Performance Journal 19(1): 43-50.

BITRE. 2009. Cost of road crashes in Australia 2006. Bureau of Infrastructure, Transport and Regional Economics Canberra. Australia. 110 p.

CAPMAS. 2015. Inventory of Licensed vehicles. Central Agency for Public Mobilization and Statistics, Cairo. Egypt.

Chang, G.; Xiang, H. 2003. The Relationship between Congestion Levels and Accidents. Report No. MD-03SP 208B46. University Of Maryland. College Park. Baltimore. 111 p.

Downs, A. 2004. Why Traffic Congestion is here to stay.... and Will Get Worse. University of California, Davis. USA. 8 p.

EL-Shourbagy, M.; Abo-Hashema, M.A. 2000. Traffic analysis on main corridor in Mansoura city, Dakahlia Governorate, Journal of Al Azhar University Engineering Sector 4:616- 624 .

FHWA. 2014. Traffic Monitoring Guide, Chapter 3: Traffic Monitoring Methodologies. Available from internet: <www.fhwa.dot.gov>.
Forbes, G.J. 2012. Methods and Practices for Setting Speed Limits. Washington D.C. USA. 107 p.

GTTA. 2008. Costs of road congestion in the Greater Toronto and Hamilton Area: impact and cost benefit analysis of the Metrolinx Draft Regional Transportation Plan. Greater Toronto Transportation Authority, Toronto. Canada. $122 \mathrm{p}$.

Hansen, I. 2001. Determination and Evaluation of Traffic Congestion Costs, European Journal of Transport and Infrastructure Research 1(1): 61-72.

HCM. 2010. Highway Capacity Manual - $5^{\text {th }} \mathrm{ed}$. Transportation Research Board. Washington D.C. USA. 1650 p.

Ibrahiem, D.M. 2015. Evaluating Cost of Air Pollution from using Fossil Fuels in Some Industries in Egypt, Advances in Management and Applied Economics 5(1): 27-39.

Khan, T.; Islam, R.M. 2013. Estimating Costs of Traffic Congestion in Dhaka City, International Journal of Engineering Science and Innovative Technology 2(3), 281-289.

Lagune-Reutler, M.; Guthrie, A.; Fan, Y.; Levinson, D.M. 2016. Transit Riders 'Perception of Waiting Time and Stops Surrounding Environments. In 95 ${ }^{\text {th }}$ Annual Meeting of the Transportation Research Board, $17 \mathrm{p}$.

Litman, T.A. 2013. Transportation cost and benefit analysis: Techniques, Estimates and Implications, $2^{\text {nd }}$ ed. Available from internet: <www.vtpi.org/tca/ tca0501.pdf $>$.

Mallela, J.; Sadasivam, S. 2011. Work Zone Road User Costs- Concepts and Applications. Available from internet: <www.fhwa.dot.gov>.

NCHRP. 2003. Design speed, Operating speed and Posted Speed Practices. Available from internet: <http:// onlinepubs.trb.org/>. 
NIT. 2016. Estimation of Economic Cost and a Plan for Reduction of Road Crashes in Egypt (In Arabic). National Institute of Transportation, Cairo, Egypt.

RACQ. 2015. Private vehicle expenses 2015. RACQ Motoring and Travel services. Queensland. Australia. 22 p.

Risbey, T.; Cregan, M.; De Silva, H. 2010. Social Cost of Road Crashes. In Proceeding of the $33^{\text {rd }}$ Australasian Transport Research Forum, 1-16.

RWDI. 2006. South Fraser Perimeter Road Regional Air Quality Assessment: Technical Volume 16 of the Environmental Assessment Application. Available from internet: <www.gov.bc.ca/tran/>.

Shoaeb, A.; El-Badawy, S.; Gabr, A. 2016. Direct Costs of Urban Traffic Congestion Case Study: Main Corridors in Mansoura City, International Journal of Computing, Communications \& Instrumentation Engineering 3(2): 244251.

TAC. 2014. Report on study of road traffic congestion in Hong Kong. Transport and Housing.Transport Advisory Committee Hong Kong. 124 p.
TAG. 2014. Transport Analysis Guidance - TAG Unit A1.3:User and provider impacts, Department for Transport, London. Available from internet: <https:// www.gov.uk/guidance/transport-analysis-guidancewebtag $>$.

The Parliament. 2008. The Traffic law No. 121, 2008, amendment of the traffic law issued by Law No. 66 in 1973 (In Arabic), Egyptian Journal Official Gazette 23: 2-20.

Wardman, M. 2004. Public Transport Values of time, Transport policy 11(4): 363-377.

Weisbrod, G.; Reno, A. 2009. Economic Impact of Public Transportation Investment. TCRP Project J-11, Task 7, Transit Cooperative Research Program, American Public Transportation Association. Washington. D.C. USA. 55 p.

World Bank. 2010. Cairo Traffic Congestion Study Phase I. Available from internet: <http://documents. worldbank.org/>.

World Bank. 2013. Cairo Traffic Congestion Study. Available from internet: <http://documents.worldbank. $\operatorname{org} />$. 